\title{
LOS MAESTROS GILABERTE, EN EL ENTORNO DE MOLINA DE ARAGÓN (GUADALAJARA), Y SU RELACIÓN CON JOSÉ MARTÍN DE ALDEHUELA
}

\author{
Rosario CAMAcho Martínez
}

\section{RESUMEN}

En este trabajo se presenta la actividad de una dinastía de maestros arquitectos del norte de Castilla, especialmente Manuel Gilaberte, que fue discípulo y colaborador de José Martín de Aldehuela, colaboración que ha permitido la atribución a éste de algunas obras, ya aclarada la autoría por la investigación documental.

\section{ABSTRACT}

This manuscript presents the activity of a northern castillian dinasty of master architects, in particular Manuel Gilaberte, pupil and co-worker of José Martín de Aldehuela, whose collaboration led to the atribution of some of his works to the alter, this now being cleared out through documental investigation.

\section{INTRODUCCIÓN}

El señorío de Molina, es un territorio amplísimo, "ancho" ha indicado A. Herrera, similar en extensión a la provincia de Álava y superior a Guipúzcoa, que cubre $3.350 \mathrm{Km}^{2}$, en 4 sesmas: el Sabinar, la Sierra, el Pedregal y el Campo, agrupando un número importante de poblaciones, que constituyen un partido judicial, cuyos límites no se corresponden totalmente con los límites históricos de la antigua entidad del Señorío, y cuya capital es Molina de Aragón, a orillas del río Gallo, plaza militar y fronteriza en el Medioevo, como demuestra la importancia de su castillo doblemente cercado ${ }^{1}$. Su topónimo también indica cambios históricos. Madoz señala como en diferentes luchas se

1. HERRERA CASADO, A.: Molina de Aragón. Veinte siglos de historia, Guadalajara 2000, $13,53$. 
dio a los nobles como pago a sus servicios por lo que los molineses entregaron el Señorío al Rey de Aragón, cambiando en otros momentos, hasta que Isabel la Católica juró que siempre el señorío de Molina estaría unido a Castilla, pero ha mantenido el topónimo de Aragón ${ }^{2}$. Por otro lado el Señorío perteneció a la provincia e intendencia de Cuenca durante los siglos XVII y XVIII, pasando sólo en 1802 a Guadalajara, y está integrado en la diócesis de Sigüenza.

\section{LA ARQUITECTURA EN EL NORTE DE GUADALAJARA}

Su cercanía y esos cambios de límites entre Guadalajara, Aragón, Cuenca, convierte a Molina en tierra de aluvión y justifica la identidad y relaciones formales de su arquitectura.

En esta zona la arquitectura se ha relacionado con el maestro José Martín de Aldehuela, a quien se han atribuido obras dada la identidad y rasgos estilísticos, que trabajó especialmente en Cuenca y norte de Teruel, zonas próximas, conduciendo esta relación a través de Manuel Gilaberte; y una obra suntuosa, como la parroquia de Orihuela de Tremedal, que éste dirigió hasta finalizarla, fue trazada por José Martín.

El proceso de renovación de iglesias que se va a llevar a cabo en el obispado de Sigüenza, podría ser la razón de diferentes influencias. Como cabeza de la diócesis, se convirtió en foco de autoridad, y la iglesia de San Francisco (Ursulinas) que realizó Manuel Serrano a partir de 1731, por encargo del obispo Fray José García, ampliando y modificando la existente, con fachada convexa, soportes sesgados y originales bóvedas, acusa rasgos de modernidad e influencia italiana ${ }^{3}$. Serrano, el único discípulo de Pedro de Ribera, es el maestro de las iglesias vallisoletanas de Renedo (1736), ésta por encargo del mismo obispo, y Rueda $(1738)^{4}$, con superficies dinamizadas ondulantes y bóvedas similares a San Francisco de Sigüenza. Pudo influir también en la arquitectura de los Gilaberte que apenas trabajaron en esta ciudad, pero no podemos olvidar que era la sede del obispado al cual pertenecía la zona de su trabajo, pues esos rasgos no son privativos suyos. Pero tanto Manuel Gilaberte en solitario como trabajando con su hermano Joaquín, cubrieron obras en todo el señorío, que nos muestran una ornamentación rococó y atractivos muros

2. MADOZ, P.: Diccionario geográfico-estadístico-histórico de España y sus provincias de Ultramar..., Madrid 1845, vol. XI, 465. HERRERA CASADO, A.: op. cit., 46.

3. ROMÁNPASTOR, C.: "La influencia del barroco madrileño en la provincia de Guadalajara", Wad-al-hayara 27, 2000, 212.

4. BRASAS EGIDO, J. C.: "El arquitecto Manuel Serrano", Boletín del Seminario de Arte y Arquitectura de Valladolid, 1978, 467-77. RODRÍGUEZ, G. DE CEBALLOS, A.: "Francisco Borromini y España", en ARGAN, G. C.: Borromini, Madrid 1987, 36. 
movidos, e incluso en intervenciones parciales transformarán los sencillos espacios estáticos de las iglesias dinamizándolos mediante el diseño curvo de los muros y el tipo y molduraje de las bóvedas.

También desde el primer tercio del siglo XVII, era notorio el influjo de Madrid. En Sigüenza, con anterioridad a Serrano, confluyeron Juan Lobera, que trazó el trasaltar de la Catedral. Otros procedían de Santander como los Villa y de la misma Guadalajara, como Francisco de Quevedo ${ }^{5}$. Por otro lado, a finales del siglo XVIII, al supervisarse los proyectos de los maestros locales por la Comisión de Arquitectura de la Real Academia de San Fernando el influjo madrileño se marcó fuertemente. Además en estos años los obispos ilustrados emprendieron importantes obras de urbanismo, beneficencia, etc. donde el peso de la Academia se hace sentir más, aunque también la diócesis hizo encargos a maestros italianos, como Bernasconi quien pudo trazar la Puerta del Mercado de la Catedral ${ }^{6}$, aunque la realizó el maestro seguntino Ramón Sierra ${ }^{7}$

Una de las obras más importantes que se realizó en Sigüenza fue la iglesia de Santa María que había trazado el maestro Julián Armero en 1791, encargándose la realización a Pedro Joaquín de la Puente Ortiz, Académico de mérito de la Academia de San Fernando desde 1789, junto con Mateo López, maestro Mayor de Cuenca ${ }^{8}$, y donde el juego de volúmenes de la cabecera con otros elementos es espectacular. La relación estilística vuelve a cerrarse con Mateo López quien colaboró con Aldehuela en diferentes obras. López, hijo del arquitecto Agustín López, de Iniesta, que llegó a ser Maestro de Obras del Obispado y Académico de San Fernando, en 1785, fue Aparejador en obras que trazó o dirigió José Martín. En un documento de 1784, en el que solicita su admisión al examen para obtener el grado de arquitecto de la Academia, informa haber dirigido como Aparejador, la capilla del Rosario de la iglesia de los dominicos de Cuenca, y la nueva iglesia de la Concepción Francisca, ambas por diseños y disposición de José Martín, así como la conclusión de San Antonio Abad, también por trazas de Martín, quien la había iniciado. En la Casa de Recogidas las relaciones se invirtieron ya que la empezó José Martín por diseños de Mateo López, que fue quien la terminó 9 .

5. ROMÁN PASTOR, C.: op. cit., 195.

6. LARUMBE MARTÍN, M.: "La época ilustrada en la provincia de Guadalajara", Wad-alhajara 26, 1999, 239-89.

7. Agradezco estos datos al padre Juan Antonio Marco, que ha revisado la documentación de estas iglesias para un estudio sobre arquitectura de la zona.

8. Archivo de la Academia de San Fernando AASF Actas de la Comisión de Arquitectura (3/139), 76 8-4-1791.

9. AASF Leg. 43-1/1 (En el expediente se citan diversas obras de este maestro que trabajó en Cuenca y provincia, así como en Murcia y Guadalajara, tanto en trabajos de arquitectura como de ingeniería). 


\section{LOS GILABERTE}

Se puede hablar de una dinastía de maestros que trabaja en el entorno de Molina. El maestro Diego Gilaberte Lichaga, vecino de Molina, trabajó en el Señorío en 1689. Manuel Gilaberte Judes, era maestro de obras, "bien conocido por las buenas obras que ha hecho". Manuel Gilaberte y Guillén, su hijo, es citado como arquitecto, aunque la titulación más utilizada es la de Maestro de Obras, y su hermano Joaquín, colaboró con él en algunas obras, aunque también trabajó solo.

Hay otra generación, pues en 1826 trabajan otros dos maestros: Joaquín Gilaberte y Beltrán (hijo de Joaquín) y Bernardo García Gilaberte ${ }^{10}$. El maestro Santiago Gilaberte, que trabaja después de 1754 en la iglesia de Maranchón también estaría relacionado con esta familia. En cambio el arquitecto establecido en Valencia, Antonio Gilabert y Fornés (Pedreguer (Alicante) 1716-1792), que primero titubea entre el barroco y su personal adscripción a las corrientes académicas, llegando a representar los comienzos de la arquitectura académica en Valencia, no parece relacionarse con éstos ${ }^{11}$.

Manuel Gilaberte Judes, en 1773, trabajaba en el Monasterio de Buenafuente y fue fiador de sus hijos en diferentes ocasiones. En 1762 intervenía en Cillas, cuya iglesia contaba con cabecera y crucero de finales del siglo XVII y ahora se reforma el cuerpo principal al que se añaden dos naves y bóvedas, obra en la que se invirtieron $19.000 \mathrm{r}$. En la misma fecha trabaja en obras accesorias a las iglesias de Torremochuela y Pradilla, (dos graneros de 4.850 r. y 1.580 r. respectivamente) $)^{12}$. En 1774 se hace cargo de las obras de Cubillejo de la Sierra, ya que a la pequeña iglesia de una nave con tres tramos se añade una capilla mayor de nueva planta, se emboveda el cuerpo central y se construye un granero, según trazas del maestro de obras del obispado seguntino Francisco Javier Delgado. La obra resultaría más compleja al querer el cura y vecinos cambiar la proporción cuadrada por la sexquiáltera, más esbelta y elegante (la unidad y una mitad más), lo que suponía levantar los muros nueve pies más y 9.000 r. El Provisor mandó revisar el proyecto al maestro Santiago Armero quien lo desaconseja y propone añadir un presbiterio, obra que se firmaría también con Gilaberte y que termina a satisfacción en noviembre de 1776. En 1826 se le añadió un crucero por Joaquín Gilaberte Beltrán y Bernardo García Gilaberte ${ }^{13}$.

10. Datos facilitados por Juan Antonio Marco.

11. BÉRCHEZ, J.: Los comienzos de la arquitectura académica en Valencia: Antonio Gilabert, Valencia 1987, 9. (La remodelación interna de la catedral de Valencia se hace a partir de 1774 siendo obispo Fabián y Fuero).

12. Datos facilitados por Juan Antonio Marco.

13. MARCO, J. A.: "La iglesia de Cubillejo de la Sierra: Arte y religiosidad", en prensa. 
Su hijo Joaquín ya trabajaba en solitario en 1785 en Tordelpalo, cuando le comunican que había presentado baja para la capilla mayor de la iglesia de Pradilla, obra de la que fue fiador su hermano Manuel Gilaberte. En esta iglesia, de una nave, llama la atención la variedad de la cubierta que dinamiza el espacio. En 1810 contrata la reconstrucción de doce casas incendiadas en Villar de Cobeta. En 1816 en Prados Redondos una torre de nueva planta con costes de 20.000r. En 1819 se encargó a Joaquín Gilaberte visitar la parroquia de San Juan de Checa (Sexma de la Sierra) que era amplia y el altar mayor con buenos adornos $^{14}$, para embovedar de nuevo la capilla mayor y el presbiterio ${ }^{15}$.

\section{MANUEL GILABERTE Y GUILLÉN}

En el sistema de relaciones laborales existentes en el Antiguo Régimen, generalmente los aprendices se integraban en la casa del maestro, como un miembro más de la familia, y esas relaciones se acrecientan si existían vínculos familiares o de paisanaje. Manuel Gilaberte y Guillén, en quien se centra este trabajo, nació en Molina de Aragón en $1750^{16}$, trabajó por tierras de Molina, avecindándose en diferentes localidades del Señorío posiblemente en relación con sus trabajos, como Molina y Terzaga, pasando en sus últimos años a Castellar, donde murió en 1810.

Se relaciona en Cuenca con Juan Antonio Aguilar (vivía en su casa, de la parroquia de San Pedro, en 1770) y con José Martín de Aldehuela, de quienes aprendería el oficio, llegando a ser discípulo aventajado de éste, ya que al pasar el arquitecto Aldehuela a Málaga se hizo cargo de sus obras en Cuenca y Teruel.

La relación con Aguilar, maestro mayor del Obispado de Cuenca, al menos desde 1764, no es sólo de aprendizaje, es un parentesco y un paisanaje porque Aguilar procedía de Molina y la relación entre ambas familias es antigua: en 1710 Manuel Aguilar y María Gilaberte, vecinos de Molina, bautizan a su hijo Manuel Aguilar Gilaberte, quien en 1764, a su vez, bautizó a Vicente, hijo de Manuel Aguilar y Antonia Guillén, que también sería familia de Manuel $^{17}$. En 1770, casó con Teresa Conejos Sancho hija de Juan Conejos, escultor de retablos (quien hizo el retablo de Orihuela del Tremedal en 1776, iglesia que proyecta José Martín y realiza Gilaberte). Ella era natural de Cor-

14. MADOZ, P: op. cit., vol. VII, 1847, 313.

15. Datos facilitados por J. A. Marco.

16. Archivo Histórico Nacional (AHN). Consejos, leg. 24.272, fol 31. El informe que firma en Zaorejas 1-7-1789, siendo vecino de Castellar, sobre el puente de piedra sobre el Tajo (destruido por los franceses) indica que es de edad de 40 años poco menos.

17. Archivo parroquial de Molina Libro 6 de Bautismos fol 12 y Libro 8 de Bautismos (Agradezco estos datos a Juan Carlos Esteban). 
balán y vivía en Cuenca en casa de su tío José Martín ${ }^{18}$. La relación se cierra más, porque éste casó en segundas nupcias, en 1776, con $\mathrm{M}^{\mathrm{a}}$ Antonia Conejos, por tanto Gilaberte, esposo de Teresa Conejos, hermana de ésta ${ }^{19}$, era también cuñado de José Martín de Aldehuela.

Gilaberte viviría en casa de su tío Juan Antonio Aguilar no sólo como familiar, sino como aprendiz y oficial de taller, como era habitual en las relaciones de aprendizaje, y fue en Cuenca donde se examinó y obtuvo el título de Maestro. Pero estas relaciones se establecen también con José Martín pues el volumen de trabajo que éste desarrolla en Cuenca parece indicar que había formado taller y tuviera oficiales y colaboradores, discípulos y la documentación cita a Gilaberte como colaborador y discípulo. Es el sistema de trabajo que propiciaba un taller lo que le permitiría acudir a los diferentes encargos, y tuvo muchos. Manuel recibiría la primera formación de su padre, maestro bien considerado en el círculo seguntino, pero posiblemente éste querría más amplios horizontes para su hijo y sería la razón por la que marcha a Cuenca, bajo la tutela de familiares bien cualificados profesionalmente.

La primera obra que conocemos en la que interviene Manuel Gilaberte es la iglesia parroquial de San Millán en Orihuela del Tremedal, diócesis de Albarracín, reedificada entre 1770-75, siendo "el Maestro oficial alarife que la construyó D. José Martín Maestro Mayor de Obras del Obispado de Cuenca y natural de Manzanera, obispado de Teruel". "El segundo maestro y sobrino suyo se llamaba Manuel Gilaberte, natural de la villa de Molina", como indicaba un rótulo que se colocó en la última piedra.

La primitiva parroquia de Orihuela, que ya existía en el siglo XVI, era pequeña y estaba "muy deteriorada en lo material de su obra por tener el testero del coro cerramiento de ella junto con parte de la torre quebrantado, desplomada su fachada exterior y retirado parte de las paredes de sus costados, sobre los que cargaban los movimientos de arcos y bóvedas, que en pocos años hubiera experimentado ruina". Los vecinos deseaban construir una más grande y en mayo de 1769 lograron el permiso del obispo de Albarracín, D. José Molina Lario, quien solía ir a descansar y meditar al santuario de la Virgen del Tremedal, sufragándola con el producto de la Herrería y Montes y trabajo del pueblo. El Cabildo de Albarracín se opuso al proyecto al conside-

18. Contrae matrimonio en la parroquia de San Gil. Archivo Diocesano de Cuenca (A.D.C.) Sección Curia Eclesiástica Audiencia Caja 1418 año 1770. Parroquia de San Gil Libro de Matrimonios 184 (1654-1791), fol 126.

19. Se les dispensa del impedimento de parentesco de $3^{\circ}$ y $4^{\circ}$ grado de afinidad (del Libro 6 y también: 13-5-1778. Pedro Saiz natural de Cuenca casa con María Marco, hija de Francisco Marco y María Martín, natural de Manzanera. Testigo: Julián de la Orden (Agradezco estos datos a J. C. Esteban). Los Marco se trasladan también a Cuenca y después a Málaga, María Martín era tia de José Martín de Aldehuele.. 
rar que aquella estaba en buen estado pero el obispo cortó sus pretensiones, justificando su licencia y acuerdo para nombrar director de la obra a "Joseph Aldehuela, uno de los maestros de mayor fama que se conocen por esta tierra", que aunque en 1773 había delegado en su sobrino Manuel Gilaberte, "por cuya dirección corre la sobredicha fábrica”, seguía siendo el maestro de la obra, como atestigua documentación de 1774 y aún posterior, bendiciéndose en septiembre de $1775^{20}$.

Esta iglesia que se levantó sobre el solar de la anterior, y a la que se pueden aplicar los adjetivos con que la designó el Cabildo de Albarracín en 1772, "sumptuosa y crecida”, aprovechó parte del presbiterio de la iglesia antigua, "para conservar sin quebranto el altar mayor" ${ }^{21}$ y es una de las obras más monumentales de Aldehuela.

Tiene tres naves separadas por un doble orden, corintio hacia la nave central y con capitel ménsula apoyando los arcos formeros, que enriquece notablemente los perfiles, y sostienen entablamento con dobles dentículos que se transforma en arquivolta de los arcos, alternando su altura y su luz. Tiene tribuna a los pies, con balconcillo convexo, cubriéndose el sotocoro con bóveda de cañón muy rebajado con lunetos curvos, y la nave central cubre sus tramos con bóvedas del mismo tipo, con molduraje para disponer pinturas y lunetos con guirnaldas y querubines que encierran ventanas elípticas. En el crucero se alza una cúpula sobre pechinas con querubines en sus ángulos, y se abre con linterna de ventanas curvas, encastrándose por la clave un cascarón muy rebajado con cupulín. Sus brazos delimitan testeros curvos y se cubren con bóvedas de horno, nervadas, abiertas con ventanillas ovales que proyectan amplia luz en este espacio, con ecos del barroco alemán. En la capilla mayor el retablo, realizado por Juan Conejos, que sigue pautas del barroco tradicional, es el de la iglesia antigua, de comienzos del siglo XVIII, pero el manifestador, con estípites y gran énfasis dinámico y con las pequeñas esculturas responde al estilo de Aldehuela. Exteriormente es obra de mampostería muy cuidada en cuyos laterales se señalan los huecos elípticos con molduras que parecen modeladas. La fachada es de sillería, recorrida por un apilastrado muy plano flanqueando el cuerpo central, con

20. Archivo Parroquial de Orihuela del Tremedal. Libro de Bautismos que comienza en 1770. Documento inserto en el fol. 49. Agradezco al párroco D. Alejandro Yuste, las facilidades para investigar en el archivo.

TOMAS LAGUIA, C.: "Las iglesias de la diócesis de Albarracín", Teruel 32, 1964, 83-92. En la documentación de 1772 citada por Laguía se encuentra por primera vez el sobrenombre de Aldehuela para designar al arquitecto.

Archivo Parroquial de Orihuela del Tremedal. Libro Padrón para la cuentas de este lugar de Orihuela, partido de Albarracín, que comienza en 1770., fol. 66.

21. TOMAS LAGUIA, C.: op. cit., 90-1. 
un gran arco ciego con orejetas coronado por frontón triangular y aletones laterales. El tímpano se cala con un óculo oval ante el que campea el remate del pabellón acampanado que corona el pórtico, detalle muy borrominesco. En el último tramo de la nave del Evangelio se alza la torre.

Se ha relacionado con esta iglesia la de la Casa Grande de la Baronía de Escriche (Teruel) ${ }^{22}$. Y no sólo por el estilo sino porque la familia del comitente, el barón de Escriche, poseía en la parroquia de Orihuela la capilla de San Fabián y San Sebastián, en la iglesia antigua y que se mantendría en la nueva. El conocimiento de esta iglesia y de las ideas de Aldehuela queda asegurado por esta vía y el barón pudo inclinarse por este estilo ya sea a través de él directamente o de sus colaboradores como lo fueron Manuel Gilaberte Guillén y Juan Chavarría Domingo ${ }^{23}$.

A pesar de su estado de ruina la iglesia recuerda el estilo de Orihuela de Tremedal y puede responder a un diseño de Aldehuela, pero también podría ser de Manuel Gilaberte que prolonga el estilo del maestro en el norte de Teruel y Guadalajara.

Datos indirectos nos indican que en 1777 Manuel Gilaberte había presentado un proyecto para realizar un crucero en la iglesia de Alustante, y en 1778 dio traza y condiciones para una iglesia de nueva planta en Chequilla, indicándose que es "maestro arquitecto y alarife bien conocido en este obispado". Este proyecto junto con otro de Francisco Javier Delgado, maestro de obras de Sigüenza, fueron enviados en 1781 a la Academia de San Fernando, posiblemente por segunda vez, y no se aprobaron. Construyó la iglesia Diego Ruiz Torremilano, vecino de Molina, por las condiciones del maestro Delgado y revisadas por Juan Manuel de la Cuadra ${ }^{24}$.

La parroquia de Terzaga (Guadalajara), patrocinada por el arzobispo de Valencia Fabián y Fuero, se ha atribuido a Aldehuela por la identidad estilística ${ }^{25}$, sin embargo he podido documentarla como traza de Manuel Gilaberte Guillén de $1777^{26}$. Verdaderamente está próxima al estilo de Aldehuela, lo que demuestra la relación maestro-discípulo. Con su cabecera trebolada, cúpula en el crucero, corto tramo de nave cubierto con bóveda vaída y de horno, el alabeamiento de los muros, el alzado compuesto, los tramos convexos, las ménsulas, los querubines, el bulboso púlpito, etc. bien puede justificar la atribución.

22. SEBASTIÁN, S.: Inventario artístico de Teruel y provincia. Madrid 1982, 196-7.

23. PÉREZ HERNÁNDEZ, Ma J.: "La Casa grande de la baronía de Escriche: Pintura profana y arquitectura", Seminario de Arte Aragonés XLV, 1991, 61.

24. MARCO MARTÍNEZ, J. A.: "Las iglesias de Miralrío y Membrillera", Actas del VII Encuentro de Historiadores del Valle del Henares, 2001, 617-8.

25. MUÑOZ JIMÉNEZ, J. M.: "El arquitecto José Martín de Aldehuela y la iglesia parroquial de Terzaga", Academia 74, 1992, 377-98.

26. Archivo Diocesano de Sigüenza. A.D.S. Sección Documentos Civiles. 1777. 
Terzaga contaba con una parroquia pequeña, y dos importantes prelados, naturales de ésta, el arzobispo de Valencia D. Francisco Fabián y Fuero, que anteriormente había sido obispo de Puebla, y D. Victoriano López, después obispo de ésta, construyeron a sus expensas una iglesia nueva y más capaz cuya traza y construcción corrió a cargo de Gilaberte "maestro de habilidad que la desempeñará con todo el primor del arte". En 1777 dio las condiciones para la construcción de esta nueva iglesia, que se levantaría junto a la antigua y de la cual sólo se iba a conservar la pared del presbiterio con su retablo, y al mismo tiempo se obliga a ejecutarla de acuerdo con estas condiciones. La iglesia se bendijo el 11 de junio de 1781. Su hermano Joaquín colaboraría en la obra pues vive entre 1778-80 en Terzaga en donde bautiza a dos de sus hijos ${ }^{27}$.

Pero la iglesia pronto necesitó obras. Tal vez porque los fondos aportados por el arzobispo no cubrieran lo proyectado, o porque se hiciese alguna parte provisional; no pienso que fallase el maestro porque de ser así no hubieran recurrido al mismo. Efectivamente en 1784 Fray Pascual Sanz, religioso del convento de San Francisco de Molina y cura ecónomo de la parroquia de Terzaga, inició las gestiones para reparar la iglesia, a costa de la fábrica, encargándosele al mismo Gilaberte, que entonces era vecino de Terzaga, al que acepta por ser maestro "de la mayor satisfacción, habilidad, inteligencia y práctica", en virtud del acuerdo que había firmado con el párroco anterior en julio de 1783 y ya estaba trabajando en ella según escritura firmada, y según las condiciones que dio el maestro Gabriel García, vecino de Inojosa.

A su término, en 1785 fue reconocida por el maestro de Sigüenza Felipe Delgado (que estaba reparando la iglesia de Torquemada), aprobando la obra, realizada de acuerdo con las condiciones, que afectaba fundamentalmente a la "ampliación de la media naranja". Esto nos indica una ampliación respecto al proyecto primitivo en la media naranja del crucero, pero también una intervención necesaria en las demás bóvedas que constituían la cubierta. En 1799 continuaban obras por 40.000r que lleva a cabo Ramón Sierra y pagó Victoriano Flores.

La iglesia, con su capilla mayor y brazos de crucero en forma absidial, forma un poderoso cuerpo trebolado alrededor de la cúpula levantada sobre anillo denticulado y se apoya en pechinas de curvados ángulos flanqueados por querubines. La nave propiamente dicha tiene tres tramos, de lados ligeramente curvos, cubiertos con bóvedas vaídas de lunetos curvos y con pinturas, prolongándose con un pequeño coro cuadrado. El alzado lo constituyen hermosas columnas adosadas, con robustos capiteles compuestos que sostienen un elevado entablamento resaltando sobre aquellas al modo del dado siloesco, e imprimiéndole un fuerte movimiento; remata con cornisa taqueada que re- 
sulta especialmente atractiva en el centro de la nave configurando un frontis convexo dentro de un diseño clásico. El movimiento y resalte de los muros se acrecienta con recuadros y molduras, guirnaldas, querubines, etc., sosteniendo el forjado del coro las típicas orejetas o ménsulas, tan empleadas por Aldehuela. El exterior no anuncia la riqueza del interior, ni el movimiento; presenta volúmenes prismáticos, contrafuertes, fábrica de mampostería y sillería en los ángulos y el único rasgo más vistoso es la torre, de piedra sillar, con un sobrio juego de fajas verticales en su caña, coronada con alto chapitel.

Las mismas formas encontramos en otras iglesias de la cercana Molina de Aragón de donde era natural Manuel Gilaberte y en donde trazó algunas iglesias e intervino en la remodelación de otras, como la del convento de San Francisco, cuya obra, costeada por Fabián y Fuero, terminó en $1777^{28}$. El convento, fundado en 1284 por $\mathrm{D}^{\mathrm{a}}$ Blanca de Molina conserva restos antiguos. La remodelación afectó a toda la iglesia (se levantan los muros que serán curvos en el crucero y se aboveda por completo) y a la capilla de la VOT, y es especialmente notoria en su torre de sillares, cuya caña es, como en otras obras de Gilaberte, sencilla de líneas pero la potencia que tienen los capiteles del cuerpo de campanas, jónicos con guirnaldas pendientes, le imprimen un mayor decorativismo; por encima de este cuerpo, rematado en pináculos, se alza el chapitel, de piedra, en forma de pirámide rematada por el famoso Giraldo. La portada lateral, mucho más clásica, coronada con frontón es obra de 1809, y podría atribuirse por sus relaciones con la portada del Mercado de la Catedral (1796) al maestro seguntino Ramón Sierra.

En San Miguel, de Molina de Aragón, (desaparecida) se documenta a Manuel Gilaberte padre, "maestro de obras de esta villa y uno de los más acreditados", y al hijo "maestro de obras bien conocido por su habilidad dentro y fuera de este obispado", a quien en 1776 se contrató la reparación de los desperfecto ocasionados por el viento en la "cruz, veleta y bola que sirven de remate al capitel de la media naranja”. Pero serían más obras, de otro modo no se podrían justificar los 1950 r. en que contrató las obras ${ }^{29}$

La parroquia de San Martín, la más antigua de Molina, reedificada en el s. XII, conserva el presbiterio y el muro meridional. En 1794 su párroco, Juan Ruimonte, remitió a la Academia de San Fernando dos planos, condiciones y avance del Profesor D. Manuel Gilaberte y Guillén, residente en Castellar, "para la construcción de la torre, linterna y ornato de la parroquia" y que se rechazó todo "por no hallarse inteligencia del arte en las partes

28. En documentación de Terzaga, de 1777, alude a que ha terminado S. Francisco (Dato facilitado por Juan A. Marco).

29. Dato facilitado por J. A. Marco. 
sustanciales, y en las accesorias todo el mal gusto imaginable" 30 , y se hace una cerca exterior y torre campanario .

Juicio duro sin duda pero, evidentemente, el personal estilo de Gilaberte ligado a los cánones del rococó, no podía ser aprobado en esa fecha en la Academia, paladín del nuevo gusto clasicista. Pero la obra urgía y se encargó al académico Carlos de Vargas Machuca, quien presentó tres diseños que se aprobaron inicialmente pero debía pasarlos a limpio para cotejar ambos trabajos. Carlos de Vargas Machuca se formó con Juan Pedro Arnal, que era entonces Director de Arquitectura, y fue éste el encargado de supervisar las correcciones, obviando pasarlas nuevamente por Comisión, lo que se haría ya definitivamente en agosto de ese año, resaltándose especialmente el diseño de la torre, que satisfizo plenamente a Arnal "por haberse ceñido a las particularidades que dijeron los interesados en la obra" 31.

La pureza de líneas de la torre, las elegantes pilastras que flanquean su vano, de escaso resalte, responden al gusto que se impone desde la Academia. Vargas Machuca que se integró en el Cuerpo de Ingenieros Militares, tradujo en 1795 la obra de Palladio ${ }^{32}$ para los estudios de la Academia, con clara influencia de Arnal, completando su visión teórica, y será uno de los artífices de nuestra arquitectura neoclásica. Lógicamente la difusión de estos estudios incidió en el haber cotidiano de la arquitectura de finales de siglo, a la que pertenecería plenamente este diseño ${ }^{33}$, que no fue una gloria para Vargas Machuca, quien lo realizó sin conocer la iglesia, apoyándose en el de Gilaberte. Pero al ejecutarse la obra fueron surgiendo dificultades que resolvía el Maestro de Obras del Obispado Pedro Baraya y después Ramón Sierra, que a partir de 1799 aparece como "maestro arquitecto de la Real Academia de San Fernando y titular de la Sta. Catedral de Sigüenza", que a juicio de Marco son los arquitectos de más prestigio del obispado de Sigüenza en los años finales del s XVIII. Terminó la obra Pedro Laentrada, vecino de Zaragoza ${ }^{34}$.

En 1783 Gilaberte interviene en Castellar de la Muela de donde era vecino. Esta iglesia, una de las mejores de la zona, se la había atribuido por sus caracteres estilísticos y dado que Manuel Gilaberte, se avecinda y se había retirado a esta localidad, no me parecía extraño que interviniera en la iglesia.

30. AASF Actas de la Comisión de Arquitectura (3/139), fol. 248.

31. AASF Actas de la Comisión de Arquitectura (3/139), fols. 249v y 255v.

LARUMBE MARTÍN, M.: "La época ilustrada en la provincia de Guadalajara", Wad-AlHayara 23, 1996, 240 y 254.

32. Colección de los edificios y planos del célebre Andrea Palladio. Madrid 1795.

33. SAMBRICIO, C.: La arquitectura española de la Ilustración. Madrid 1986, 88, 102, 167, 187.

34. MARCO MARTÍNEZ, J. A.: "Las iglesias de Miralrío”, 620. 
J. A. Marco aportó los datos documentales ya que se contrata con Gilaberte levantar cuerpo y crucero de nueva planta por 11.200 r. más 3.410 r. de mejoras. La torre puede que la hiciera hacia 1790.

Exteriormente presenta los volúmenes prismáticos y sencillos de las anteriores y la misma fábrica de mampostería, pero con cantoneras de piedra, emergiendo el volumen prismático del crucero, y a los pies una sencilla torre cuadrada de la misma fábrica. La capilla mayor es la antigua, gótica; pero su interior es mucho más rico, con un alzado de pilastras jónicas rematadas por alto entablamento, bóveda de gajos, cubriéndose los brazos del crucero con bóveda de cuarto de esfera gallonada, y otras fantasías en las bóvedas de los espacios ante el presbiterio.

En 1786 dio la traza para intervenciones en la iglesia de Setiles, que se reforma en la bóveda del crucero y coro, trabajando aquí con su hermano Joaquín, "maestro de arquitectura, albañilería y carpintería toscana", siendo fiador el padre. Es una obra considerable presupuestada en $10.950 \mathrm{r}^{35}$. La iglesia es pequeña, de una nave y el espacio central aparece dominado por la bóveda vaída sin decorar en el que se inserta por un lado el coro y por otro el presbiterio, enlazando el ábside central y dos capillas curvas más pequeñas que forman un frontis de triple arco abovedado con lunetos curvos.

En 1790 Manuel Gilaberte y Guillén, "maestro arquitecto examinado y vecino del lugar de Castellar", desarrolla una amplia intervención en la parroquia de Pardos que se ajusta en 21.500r. Primero afectó al crucero y reconstrucción total de la nave, después se reforma la cabecera y la espadaña. Es curioso que el pueblo prefirió una espadaña a los pies que reconstruir la torre que estaba en la cabecera. Una nueva escritura se firma en 6-2-1791 y están presentes Joaquín, maestro de obras de albañilería, vecino de Setiles y el padre ${ }^{36}$.

En el norte, en la Sexma del Campo, intervienen los dos hermanos en la iglesia de Anchuela del Campo, cuyos planos presentó Joaquín. Aquí había que desmontar la iglesia, ejecutar dos capillas en el crucero "que había de ser de figura curva como el de la orden Tercera de Molina" y abovedarla entera de nuevo. Es una iglesia nueva que cubre su presbiterio curvo con bóveda de cascarón, y a cada lado del crucero la misma cubierta. El contrato se firmó en 1791 y las obras se presupuestaron en $19.000 \mathrm{r}^{37}$. La obra fue posible por las aportaciones de un indiano natural del pueblo, José Pérez Gil, en 1791,

35. Archivo Histórico Provincial de Guadalajara (AHPG) Leg. 1874. (Dato facilitado por J. C. Esteban).

36. Agradezco estos datos a J. A. Marco.

37. AHPG leg. 1872-I. 
según $\mathrm{Madoz}^{38}$, y en 1792 según una inscripción de la iglesia. Pero hubo más contribuciones ya que otra inscripción indica que la iglesia y pórtico fueron costeadas a expensas de Don José Pérez y los vecinos. Aún otra tercera: "Se concluyó a devoción de Manuel Andres, cura de esta parroquia". Y en la portada "Año de 182.." 39

En Ablanque, había trabajado Pedro Baraxa, maestro de obras de Sigüenza. En 1794 intervinieron los Gilaberte siendo el padre fiador. Aquí tuvieron que desmontar el testero de la capilla mayor, hacer de fábrica la media naranja y embovedar el cuerpo de la iglesia, lo que presupuestaron en $7.000 \mathrm{r}$, ayudando los vecinos del pueblo con hombres y materiales ${ }^{40}$. Como las otras iglesias ésta también responde a una sencilla planta longitudinal pero se dinamiza y magnifica mediante un alzado de columnas toscanas de piedra y asimismo la cubierta, diferenciándose tramos resueltos con dinamismo y cierto empaque. La capilla mayor presenta una sencilla bóveda de horno y ante ella un crucero cubierto con bóveda semiesférica sobre tambor decorado con molduras anulares sujetos por querubines como en los nervios de la bóveda.

En 1795 el Obispo Fabián y Fuero que, tras acusaciones políticas se había retirado a Terzaga ${ }^{41}$, por su devoción a san Pascual Bailón tuvo mucho contacto con Torrehermosa (Zaragoza) de donde éste era natural y promovió obras en la parroquia reedificando a sus expensas la media naranja y la torre. Pudo recurrir a los Gilaberte con quienes había tenido contacto, y además era diócesis de Sigüenza.

En 1797 el maestro Manuel Gilaberte reedificó de nueva planta por 20.000 r. la iglesia de Chera, que revisó Pedro Baraya ${ }^{42}$. La iglesia, de una nave, cubre la capilla mayor y brazos del crucero con medio cañón con lunetos curvos y en el crucero una hermosa cúpula. Al exterior destaca la cuidada mampostería, el volumen poligonal del cimborrio, la torre rectangular a los pies, y un acceso abocinado, con buena sillería.

Finalmente quiero indicar que Manuel Gilaberte, siendo discípulo y colaborador de Martín de Aldehuela, debió formarse también en la arquitectura hidráulica, por eso no es extraño que lo encontremos en 1789 proyectando el nuevo puente de San Pedro en el río Tajo y una hijuela sobre el Gallo en el término de Molina de Aragón, aunque la obra no se realizó de acuerdo con su proyecto.

38. MADOZ, P.: op. cit., vol. II, 1845, 274.

39. AZCARATE, J. M $\mathrm{M}^{\mathrm{a}}$ (Dir.): Inventario artístico de Guadalajara y su provincia, Madrid 1983, Tomo II, 69.

40. AHPG leg. 1873-I.

41. ESTEBAN LORENTE, J. C.: "Un obispo regalista del siglo XVIII natural de Terzaga: Don Francisco Fabián y Fuero, arzobispo de Valencia", Wad-al-hayara 13, 1986, 327.

42. MARCO MARTÍNEZ, J. A.: "Las iglesias de Miralrío", 611. 
Las villas de Molina y Zaorejas promueven la obra, pues destrozado el puente de piedra durante la Guerra de Sucesión, desde 1771 pretendían reedificarlo, pero no contando con fondos para acometer una obra sólida de piedra, ni siquiera aprovechando los restos existentes, se hacía de madera y tan frágil que con los embates del agua no tenía duración. Dada la enjundia de la obra recurren al Consejo de Castilla para que las villas de treinta $\mathrm{Km}$. a la redonda que se beneficiarían de esta mejora en la comunicación, aporten fondos a la obra. Proponen para el proyecto y tasación a Manuel Gilaberte "Maestro inteligente en sillería y cantería", vecino de la villa de Molina ${ }^{43}$.

El proyecto del puente de piedra sobre el Tajo, junto con un plano de la zona y otro puente sobre el río Gallo están fechados en Terzaga el 8 de abril de 1789. Enviados a la Academia de San Fernando en 1792 los planos "executados por el Profesor D. M. Gilaberte" no se aprobaron y se encargaron a un maestro examinado por la Academia, nombrándose a Manuel Turillo ${ }^{44}$, que había ingresado en la Academia en 1765, siendo también alumno de Arnal, y en 1784 Académico de Mérito, alegando siempre sus conocimientos en arquitectura hidráulica ${ }^{45}$. Turillo no podría hacerse cargo de la obra, encargándosela a un maestro que estuviera en la proximidad, recayendo el encargo en el maestro de Iniesta residente en Cuenca, Mateo López ${ }^{46}$, quien había colaborado con Aldehuela.

El expediente de Gilaberte para el puente de San Pedro, que es de un solo arco, y se levanta sobre los restos del antiguo, presenta tres plantas y un alzado, mostrando el arco, un puntiagudo tajamar sobre el cual se alza un hito para la inscripción, sobre piedras de toba y va a desembocar ante la ermita de San Pedro. De las plantas, la superior muestra los restos antiguos, el tajamar y cómo se han de trabar las piedras que van enjarjadas y abajo la planta definitiva de cómo ha de quedar la obra. El 4 es el perfil transversal (Fig. 1).

En el del puente sobre el Gallo, la planta 1 presenta la estructura simple, la 2 la conclusión del puente, el 3 es un perfil vertical que muestra un puente hermoso con su antepecho sobre modillones, el hito para la inscripción, el arco bien trazado apoyado en los machones, que aquí se detallan, especificando claramente los modillones. El 4 es el perfil transversal mostrando el arco cortado por la clave.

El proyecto de López para el puente de San Pedro, fechado en Cuenca en diciembre de 1793, es más técnico y tiene más detalle, presentando los planos del zampeado y pilotaje, un corte interior por medio del macizo de la fábrica,

43. AHN Consejos, leg, 24.272.

44. AASF Actas de la Comisión de Arquitectura (3/139), fol. 206v (10-10-1792).

45. SAMBRICIO, C.: op. cit., 433-5.

46. AASF Actas de la Comisión de Arquitectura (3/139), fol. 208v (3-11-1792) SAMBRICIO, C.: op. cit., 353. 
y en el centro vista del alzado: también es un arco entre dos tajamares pero parece más sólido por los zampeados; abajo planta inferior y plano superior del puente y aparte la ermita. El del Gallo prácticamente es una versión más reducida del anterior y con mucho detalle para la cimentación (Fig. 2).

Según Sambricio, López no fue alumno de la Academia y habiéndose formado en estudios paralelos a los impartidos en San Fernando, como arquitecto práctico, lo mismo que Aldehuela, desde los primeros momentos mantiene una actitud de enfrentamiento a los supuestos formales formulados por ésta, planteando polémicas y suscitando críticas que reflejan cómo su formación basada en la tradición local se encuentra alejada del saber teórico de clasicismo. Pero alcanzó puestos importantes y en 1784 solicitó ser examinado por la Academia, siendo aprobado en 1785. En 1769 fue nombrado arquitecto de $\mathrm{Cuenca}^{47}$, en 1771 Maestro Mayor de este Obispado, a la vez que Aldehuela, y en 1775 Maestro Titular de la Provincia ${ }^{48}$. En 1785 construyó un puente en el Molino de Picasso, con Aldehuela, en Villanueva de la Zara, en la Vera del Júcar ${ }^{49}$ y en el mismo año la villa de Jorquera solicita se le nombre en lugar de Regalado Rodríguez para informar sobre el puente de este lugar; la Academia accede pero al año siguiente se lamenta por el proyecto de éste ${ }^{50}$. Tenía pues experiencia cuando se hace cargo de reconocer los puentes de San Pedro y el del Gallo y de revisar los informes y cálculo, presentando el suyo en 1794 que calculó en 152.808 el $1^{\circ}$ y 83.870 el 2 . La Comisión los aprobó excepto las entradas y salidas de ambos que se dijo debían suavizarse dándole menos declive con la rebaja de los arcos, de permitirlo la fuerza de las aguas. También se comprobó que uno de los puentes tenía interrumpida la franja de antepecho del ojo central proponiéndose que se informase sobre ello ${ }^{51}$. Y con arreglo a éste se haría la obra

En conclusión, tras este recorrido puede concretarse que nos encontramos con un rico panorama. Es una etapa de aumento poblacional, y regeneración económica que influye en la arquitectura, y la presencia de los Gilaberte unifica el estilo de esta zona del Señorío de Molina, acusando la influencia del este, especialmente de Cuenca a través de Aldehuela, aunque también influyen otros maestros ligados al último barroco.

En general, son iglesias de modestas dimensiones que exteriormente presentan una fábrica uniforme manteniendo el diseño austero, y con más espa-

47. AASF Armario $n^{\circ} 1$, leg. 43.

48. AASF Junta Ordinaria de 5-12-1784 (presenta memorial exponiendo títulos y cargo).

49. AASF Actas Comisión de Arquitectura (3/139) 1, 21-4-1786.

50. AASF. Actas Comisión de Arquitectura. 5, 28-7-1786).

51. AASF Actas de la Comisión de Arquitectura (3/139), fol. 247v. (8-5-1794). 
dañas que torres, que suele colocarse a los pies. El contraste con el interior es grande ya que aún manteniendo rígidos esquemas de planta, al menos exteriormente, los espacios se dinamizan mediante el diseño de los muros, los alzados, la superposición de pilastras y la originalidad de las bóvedas. 

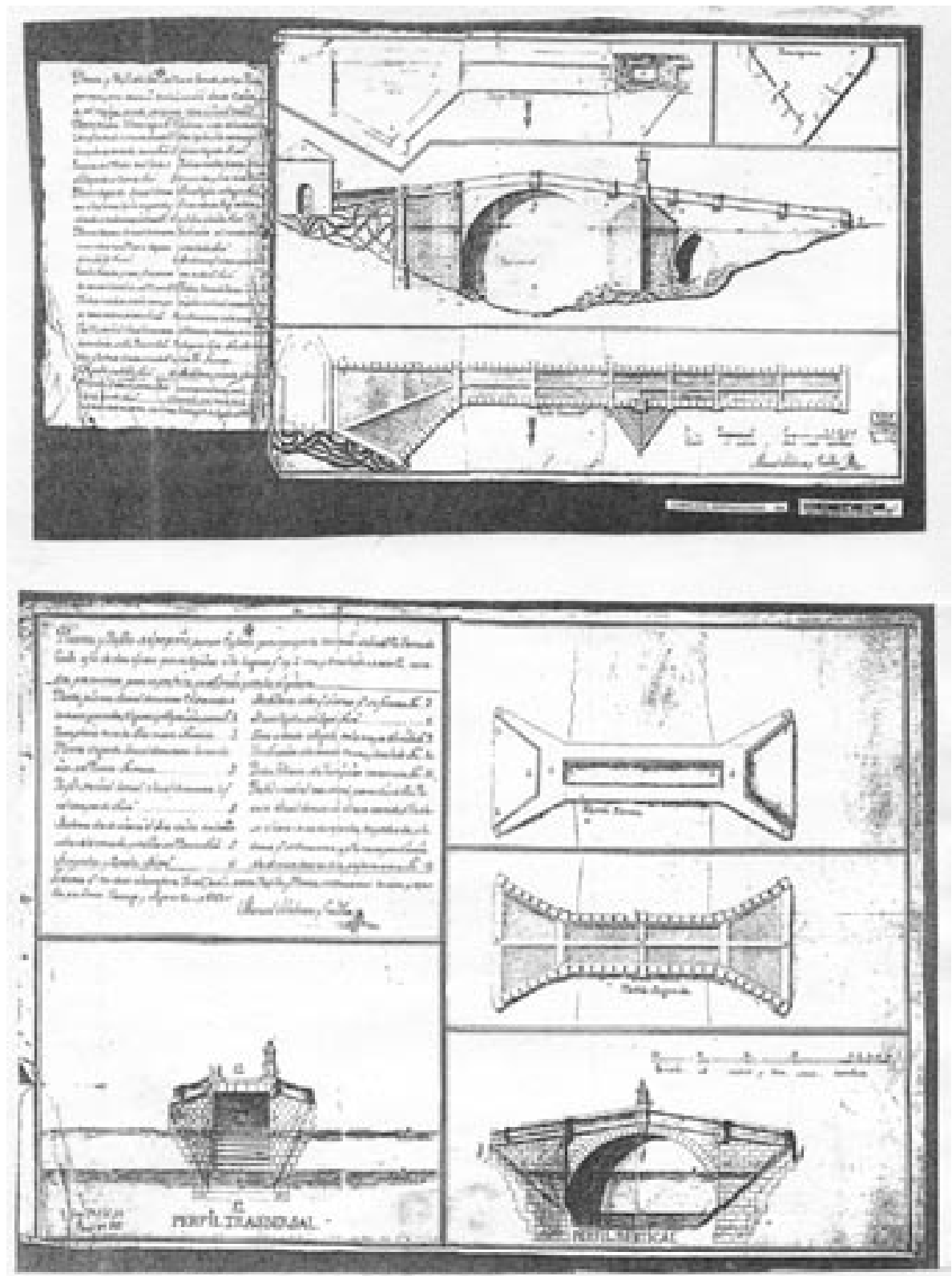

1. Proyecto de Manuel Gilaberte sobre el río Tajo y sobre el río Gallo. 

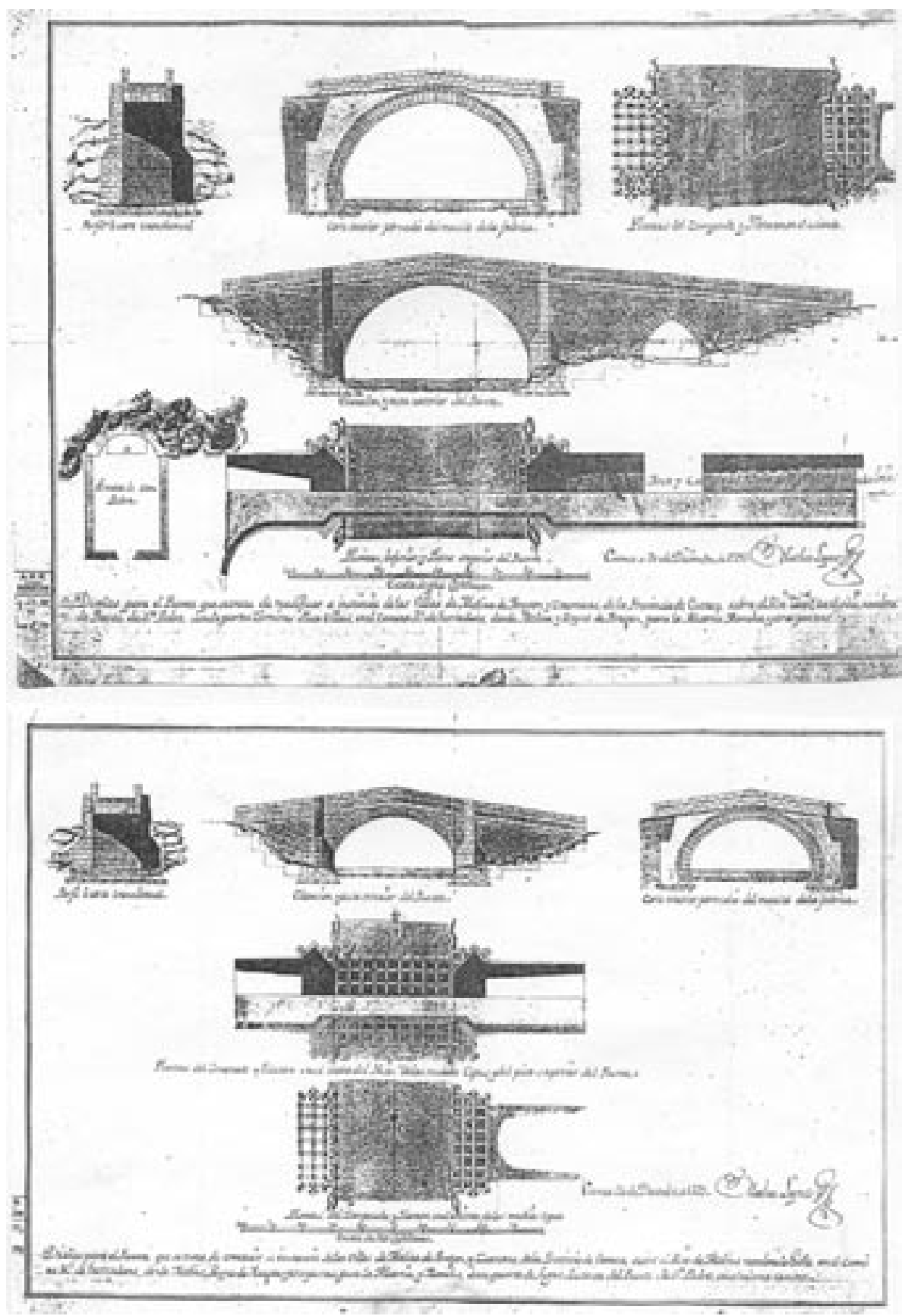

2. Proyecto de Mateo López sobre el río Tajo y sobre el río Gallo. 